\title{
Effects of rapamycin on social interaction deficits and gene expression in mice exposed to valproic acid in utero
}

\author{
Hiroko Kotajima-Murakami ${ }^{1,2}$, Toshiyuki Kobayashi ${ }^{3}$, Hirofumi Kashii ${ }^{1,4}$, Atsushi Sato ${ }^{1,5}$, Yoko Hagino ${ }^{1}$, \\ Miho Tanaka ${ }^{1,6}$, Yasumasa Nishito7, Yukio Takamatsu', Shigeo Uchino ${ }^{1,2}$ and Kazutaka Ikeda ${ }^{\text {** }}$
}

\begin{abstract}
The mammalian target of rapamycin (mTOR) signaling pathway plays a crucial role in cell metabolism, growth, and proliferation. The overactivation of mTOR has been implicated in the pathogenesis of syndromic autism spectrum disorder (ASD), such as tuberous sclerosis complex (TSC). Treatment with the mTOR inhibitor rapamycin improved social interaction deficits in mouse models of TSC. Prenatal exposure to valproic acid (VPA) increases the incidence of ASD. Rodent pups that are exposed to VPA in utero have been used as an animal model of ASD. Activation of the mTOR signaling pathway was recently observed in rodents that were exposed to VPA in utero, and rapamycin ameliorated social interaction deficits. The present study investigated the effect of rapamycin on social interaction deficits in both adolescence and adulthood, and gene expressions in mice that were exposed to VPA in utero. We subcutaneously injected $600 \mathrm{mg} / \mathrm{kg}$ VPA in pregnant mice on gestational day 12.5 and used the pups as a model of ASD. The pups were intraperitoneally injected with rapamycin or an equal volume of vehicle once daily for 2 consecutive days. The social interaction test was conducted in the offspring after the last rapamycin administration at 5-6 weeks of ages (adolescence) or 10-11 weeks of age (adulthood). Whole brains were collected after the social interaction test in the adulthood, and microarray and Western blot analyses were performed. Mice that were exposed to VPA and treated with vehicle exhibited a decrease in social interaction compared with control mice that were treated with vehicle. Rapamycin treatment in VPA-exposed mice improved social deficits. Mice that were exposed to VPA and treated with vehicle exhibited the aberrant expression of genes in the mTOR signaling pathway, and rapamycin treatment recovered changes in the expression of some genes, including Fyb and A330094K24Rik. Rapamycin treatment suppressed S6 phosphorylation in VPA-exposed mice. Aberrant gene expression was associated with social interaction deficits in VPA-exposed mice. Rapamycin may be an effective treatment for non-syndromic ASD in adolescent and adult patients who present impairments in the mTOR signaling pathway.
\end{abstract}

Keywords: Autism spectrum disorder, mTOR signaling pathway, Valproic acid, Rapamycin

\section{Introduction}

Autism spectrum disorder (ASD) is a neurodevelopmental disorder that is characterized by deficits in social interaction and communication, repetitive behaviors, and restricted interests [1]. Autism spectrum disorder has several peripheral symptoms (e.g., aberrant sensitization, clumsiness of movement, and digestive system disease),

\footnotetext{
*Correspondence: ikeda-kz@igakuken.or.jp

${ }^{1}$ Addictive Substance Project, Tokyo Metropolitan Institute of Medical

Science, 2-1-6 Kamikitazawa, Setagaya-ku, Tokyo, Japan

Full list of author information is available at the end of the article
}

but social interaction deficits are a core symptom [2]. The prevalence of ASD in school-aged children is > $1-2 \%$ [3-5], with a male/female ratio of approximately 4:1 [6]. Various genetic and/or environmental factors have been investigated in studies of ASD using animal models of syndromic ASD and non-syndromic ASD [7]. However, the pathophysiology of social interaction deficits in ASD and effective treatments have not been clarified.

Mammalian target of rapamycin (mTOR) is a serine/threonine kinase that belongs to the family of phosphatidylinositol-3 kinase (PI3K)-related kinases 
(PIKKs) [8-10]. The mTOR signaling pathway plays a crucial role in protein synthesis and cell growth, proliferation, and metabolism [10]. Overactivation of the mTOR signaling pathway causes diseases that are syndromic with ASD, such as tuberous sclerosis complex (TSC), neuronal fibromatosis 1 (NF1), and tensin homolog deleted on chromosome 10 (PTEN) [11]. Approximately $50 \%$ of child and adolescent patients with TSC are diagnosed with ASD [12]. TSC1, TSC2, PTEN, and NF1 are negative regulators of mTORC1, and mice that possess a mutation of these genes are considered animal models of syndromic ASD [13]. $\mathrm{Tscl}^{+/-}$mice exhibit impairments in learning and memory that depend on the hippocampus and a reduction of social interaction compared with wild-type mice [14]. Disturbances of excitatory/inhibitory synaptic balance are thought to be involved in the pathology of ASD [15]. Hippocampal hyperexcitability has been reported in Tsc1 knockout (KO) cultures, and Tsc1 conditional KO mice exhibited elevations of S6 phosphorylation in the hippocampus compared with wildtype mice [16]. PTEN $\mathrm{KO}$ and $\mathrm{NF1}^{+/-}$mice also exhibit social interaction deficits [17-19]. Rapamycin improved learning and memory deficits in $T s c 2^{+/-}$ mice [20]. Rapamycin treatment also recovered social interaction deficits in $T s c 1^{+/-}$and $T s c 2^{+/-}$mice and rescued the levels of phosphorylated S6K, which is downstream of the mTOR signaling pathway and involved in protein synthesis in $T s c 2^{+/-}$mice [21]. Treatment with rapamycin improved social interaction deficits and spine pruning defects in $T s c 2^{+/-}$mice [22]. Rapamycin administration in PTEN KO mice also attenuated anxiety-like behavior, attenuated sociability deficits, and increased the ratio of Akt phosphorylation [23]. Furthermore, a recent clinical study reported that everolimus, an mTOR inhibitor, ameliorated autistic behavior scores in a patient with TSC [24]. These studies suggest that overactivation of the mTOR signaling pathway is associated with ASD, and mTOR inhibition may be a potential therapeutic strategy for the treatment of syndromic ASD. However, unclear is whether rapamycin is effective for the treatment of non-syndromic ASD.

Valproic acid (VPA) is used as an anti-epileptic drug, mood stabilizer, and treatment for migraine. However, pregnant mothers who are treated with VPA have been reported to deliver children with fetal valproate syndrome and a high incidence of ASD [25]. Valproic acid is used to model non-syndromic ASD in animals. Valproic acid-treated mice and rats exhibit impairments in motor function, aberrant sensitivity, and social interaction deficits [26-28]. Valproic acid activated the PI3K/ Akt/mTOR pathway in muscle in a mouse model of Duchenne muscular dystrophy [29]. A reduction of PTEN protein levels and a higher ratio of Akt phosphorylation were found in VPA-exposed rat brains [30]. The blockade of $N$-methyl-D-aspartate (NMDA) receptors, which are upstream of the mTOR signaling pathway, attenuated social interaction deficits in VPA-exposed mice [31]. Nicolini et al. reported that the phosphorylation of mTOR, Akt, and S6 decreased in the lateral temporal neocortex in VPA-exposed rats compared with saline-treated rats [32]. A recent study reported that rapamycin treatment suppressed hippocampal neuron apoptosis in VPA-exposed rats [33]. Furthermore, rapamycin treatment attenuated social interaction deficits and the enhancement of mTOR and S6 phosphorylation in the cerebellum, prefrontal cortex, and hippocampus in VPA-exposed rats on postnatal day 33-35 (adolescence) [34]. These previous studies suggest that an aberrant mTOR signaling pathway causes ASD-like behaviors in VPA-exposed animals. However, the effects of rapamycin on social interaction deficits have not been investigated in adult mice that were exposed to VPA in utero. Moreover, gene expression analysis in whole brains has not been performed in VPA-exposed or rapamycin-treated mice. Therefore, the present study investigated the effect of rapamycin treatment on social interaction deficits in adolescent and adult mice that were exposed to VPA in utero. We also comprehensively analyzed the gene expression including mTOR signaling pathway and $\mathbf{S 6}$ phosphorylation in mouse whole brains.

\section{Methods}

\section{Animals and VPA administration}

Pregnant female C57BL/6 J mice (CLEA, Tokyo, Japan) received a single subcutaneous injection of $600 \mathrm{mg} / \mathrm{kg}$ sodium valproate (Sigma-Aldrich, St. Louis, MO, USA) on day 12.5 after conception. Valproic acid was dissolved in saline, and control mice received saline. All of the mice were returned to their home cages immediately after the injection. We used 10 dams. Eight to 10 pups were obtained from VPA- and saline-treated pregnant female mice. The pups were culled to eight animals per litter on P4. The number of mice per litter was normal compared with control mice. In this experiment, we did not observe postnatal mortality. The day of birth was recorded as day 0 , and all of the pups were labeled for individual identification. The pups were weaned, sexed, and caged in groups of 3-5 mice of the same sex on postnatal day 26 (P26). All of the behavioral tests were conducted from 9:00 AM to 6:00 PM. The mice were housed on a $12 \mathrm{~h} / 12 \mathrm{~h}$ light/dark cycle (lights on 8:00 AM to 8:00 $\mathrm{PM}$ ), and temperature was maintained at $22^{\circ} \mathrm{C}$. All of the mice had ad libitum access to food and water. In the present study, we analyzed male mice only because the prevalence of ASD is higher in males than in females. All of the animal experiments were performed in accordance 
with the Guidelines for the Care of Laboratory Animals of the Tokyo Metropolitan Institute of Medical Science, and the housing conditions were approved by the Institutional Animal Care and Use Committee.

\section{Behavioral tests}

Figure 1a shows a schedule of the experiments. The behavioral tests were conducted in a sound-proof room, and the mice were given a $60 \mathrm{~min}$ habituation period after transportation to the behavioral room before the start of each test. Body maturation was assessed by measuring body weight and eye-opening. Motor function was assessed by the righting reflex and hanging wire tests. The social interaction test was conducted in both adolescence (5-6 weeks of age) and adulthood (10-11 weeks of age).

\section{Body weight and eye-opening test}

Body weight was recorded on P7, P11, P14, P18, P21, and P25. Body weight was also recorded when each mouse underwent the social interaction test in both adolescence and adulthood. Eye opening was observed once daily from P14 to P18. The eye-opening score was the following: $0=$ both eyes closed, $1=$ one eye open, and $2=$ both eyes open.

\section{Righting reflex test}

Each mouse was placed on its back and gently held by its four limbs. The latency to right, such that all four paws were touching the surface, was recorded. The cutoff time was set at $20 \mathrm{~s}$. Each mouse underwent the righting reflex test on $\mathrm{P} 7, \mathrm{P}$, and $\mathrm{P} 11$.

\section{Hanging wire test}

The hanging wire test (O'Hara \& Co., Tokyo, Japan) was conducted from P14 to P25. The mice were placed on a grid wire surface $(150 \mathrm{~mm} \times 150 \mathrm{~mm}$, divided into 10 $\mathrm{mm}$ grid squares). The plane was inverted, and the latency to fall was recorded, with a maximum of $600 \mathrm{~s}$.

\section{Social interaction test}

We conducted the social interaction test as previously described [21]. Each mouse was left alone in its home cage for $15 \mathrm{~min}$ for habituation. The home cage was placed in a sound-attenuating chamber. An unfamiliar C57BL/6 J mouse of the same sex and age was then introduced. The behavior of the test mouse was video-recorded for $10 \mathrm{~min}$ and blindly scored for active social interaction, consisting of sniffing, allo-grooming, mounting, and following. A mouse, which went out of its home cage during the $15 \mathrm{~min}$ habituation period, was excluded from analysis. Each mouse underwent the

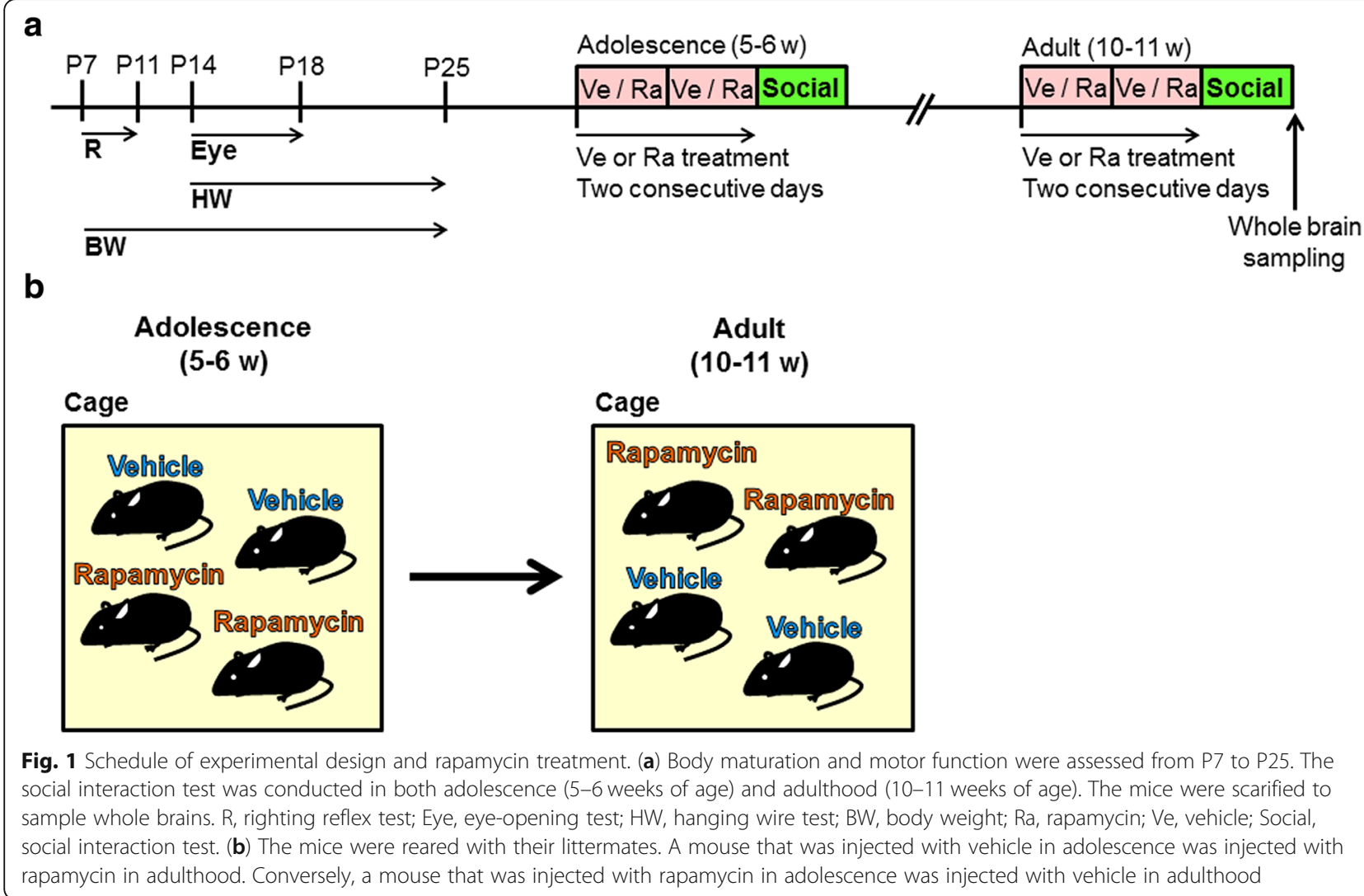


social interaction test during both adolescence and adulthood. One of the 10 rapamycin-treated vehicle mice and one of the 11 rapamycin-treated VPA mice went out of their home cages for a habituation period during adolescence. The number of mice per group was the following: adolescent $(n=11$ vehicle-treated control mice, $n=13$ vehicle-treated VPA-exposed mice, $n=9$ rapamycin-treated control mice, $n=10$ rapamycintreated VPA-exposed mice) and adult $(n=10$ vehicle-treated control mice, $n=11$ vehicle-treated VPA-exposed mice, $n=11$ rapamycin-treated control mice, $n=13$ rapamycin-treated VPA-exposed mice).

\section{Rapamycin treatment}

Rapamycin (LC Laboratories, Woburn, MA, USA) was dissolved in $10 \%$ dimethyl sulfoxide diluted with saline. The mice received a $10 \mathrm{ml} / \mathrm{kg}$ rapamycin solution or an equal volume of vehicle intraperitoneally once daily for 2 consecutive days. The dose of rapamycin was $10 \mathrm{mg} /$ $\mathrm{kg}$. Brain levels of rapamycin remained sufficiently high to inhibit mTOR throughout the $48 \mathrm{~h}$ period after rapamycin administration $(6 \mathrm{mg} / \mathrm{kg}$, i.p.) in mice [35]. Sato et al. reported that 5 or $10 \mathrm{mg} / \mathrm{kg}$ rapamycin treatment effectively attenuated social interaction deficits in $T s c 1^{+/-}$ and $T s c 2^{+/-}$mice [21]. Thus, we tested the dose of 10 $\mathrm{mg} / \mathrm{kg}$ rapamycin. The social interaction test was performed $24 \mathrm{~h}$ after the second administration. Each mouse was randomly assigned to vehicle or rapamycin administration in adolescence (Fig. 1b). A mouse that received vehicle in adolescence received rapamycin in adulthood. Conversely, a mouse that received rapamycin in adolescence received vehicle in adulthood.

\section{Brain collection and RNA extraction}

Whole brains were collected after the end of the social interaction test in adulthood. Because the precise brain regions that are associated with ASD have not yet been fully clarified, we examined whole brains in the present study. Brains were frozen in liquid nitrogen and stored at $-80^{\circ} \mathrm{C}$ until further processing. Total RNA that was extracted from whole brains was homogenized in Ambion TRIzol Reagent (Thermo Fisher Scientific, Waltham, MA, USA) using a homogenizer. RNA was isolated using chloroform and precipitated using isopropyl alcohol. The quality of RNA was assessed with Nanodrop 1000 (Thermo Fisher Scientific). All of the RNA samples had an $\mathrm{A}_{260 / 280}$ ratio between 2.0 and 2.1 and an $\mathrm{A}_{230 / 260}$ ratio between 2.2 and 2.3.

\section{Microarray analysis}

cRNA targets were synthesized and hybridized using the Whole Mouse Genome Microarray according to the manufacturer's instructions (Agilent Technologies, Santa Clara, CA, USA). The array slides were scanned using a
SureScan Microarray Scanner (Agilent Technologies). Before analyzing gene expression, microarray data were normalized and sorted using GeneSpring 14.5 software (Agilent Technologies). Each sample was normalized by a $75 \%$ percentile shift. Compromised probes were removed, and remaining probes with expression values $<20 \%$ were excluded. The probes were then filtered based on expression levels for quality control. The Benjamini and Hochberg false-discovery rate (FDR) was determined for the remaining probes and those with $p<0.05$. Each group comparison was performed using $t$-tests $(p<0.05)$. Each group consisted of five mice (vehicle-treated control mice, rapamycin-treated control mice, vehicle-treated VPA-exposed mice, and rapamycin-treated VPA-exposed mice).

\section{Mining of public databases}

The genomic data repositories in BaseSpace (illumina, https://www.nextbio.com/b/authentication/login.nb) were used to analyze all differentially expressed genes with statistical significance from vehicle-treated VPA-exposed mice vs. vehicle-treated control mice, rapamycin-treated VPA-exposed mice vs. vehicle-treated VPA-exposed mice, and rapamycin-treated control mice vs. vehicle-treated control mice. The data were compared with curated datasets that are available in BaseSpace to identify published studies of Diseases, Pharmaco, and Knockout mice using the BaseSpace Diseases atlas application, BaseSpace Pharmaco atlas application, and BaseSpace Knockout atlas application, respectively. Rank-based enrichment statistics were employed to calculate BaseSpace scores for each disease, compound, and gene for knockout mice. MetaCore (Thomson Reuters, https://portal.genego.com) was used to build the network for two negative correlation genes in vehicle-treated VPA-exposed mice and vehicletreated control mice vs. rapamycin-treated VPA-exposed mice and vehicle-treated VPA-exposed mice.

\section{Antibodies and Western blot}

Rabbit anti-S6 antibodies and antiphospho-S6 (S235/ 236) antibodies (1:500) were purchased from Cell Signaling Technology (Danvers, MA, USA). We conducted protein extraction and Western blot as previously described [21]. We prepared protein samples from the whole brain because the precise brain regions that are associated with ASD have not yet been fully clarified. Total protein from the frozen mouse brain was extracted for Western blot. Whole brains were homogenized using a tissue homogenizer in $1 \times$ sodium dodecyl sulfate (SDS) gel-loading buffer (50 mM Tris- $\mathrm{HCl}$ [pH 6.8], $2 \%$ SDS, and $10 \%$ glycerol). The supernatant was obtained by centrifugation at $17,000 \times g$. The protein concentration was determined using the Bio-Rad DC Protein Assay Kit (Bio-Rad Laboratories, Hercules, CA, USA). Equal 
amounts of extracted protein were added to $5 \%$ mercaptoethanol and boiled. Proteins were resolved by SDS-polyacrylamide gel electrophoresis (PAGE), transferred to a polyvinylidene fluoride membrane (Immobilon-P, Merck Millipore, Billerica, MA, USA), and blocked in $1 \%$ skim milk/Tris-buffered saline that contained $0.05 \%$ Tween 20 at room temperature for $2 \mathrm{~h}$. The membranes were incubated with the primary antibodies at room temperature for $1 \mathrm{~h}$. Protein bands were detected using the EnVisiont Kit (Dako, Glostrup, Denmark) and ECL Western Blotting Detection System (GE Healthcare, Buckinghamshire, UK) and quantitatively analyzed using ImageJ 1.45 software.

\section{Statistical analysis}

The results of the behavioral tests were analyzed using Statistical Package for the Social Sciences 14.0 software (SPSS, Tokyo, Japan). The data were analyzed using Student's $t$-test, the Mann-Whitney $U$ test, and two-way analysis of variance (ANOVA). All of the data are presented as mean \pm standard error of the mean (SEM).
Values of $p<0.05$ were considered statistically significant.

\section{Results}

Body maturation and motor function

The two-way ANOVA showed significant main effects of VPA treatment $\left(F_{1,43}=5.522, p=0.023\right)$ and postnatal day $\left(F_{2.026,43}=1639.1, p=0.000\right)$ and a significant VPA treatment $\times$ postnatal day interaction $\left(F_{2.026,43}=1639.1\right.$, $p=0.000 ; n=21$ control mice, $n=24$ VPA-exposed mice; Fig. 2a). The Bonferroni post hoc test showed a significant reduction of body weight in VPA-exposed mice on P18 and P25 (P18: $p=0.032$; P25: $p=0.002$ ). Eye opening scores in VPA-exposed mice were lower than in control mice on P14 $(U=125, p=0.000 ; n=21$ control mice, $n=24$ VPA-exposed mice), with no significant difference between control and VPA-exposed mice on P15 ( $p=0.114), \mathrm{P} 16(p=0.924), \mathrm{P} 17(p=1.000)$, and P18 $(p=1.000$; Fig. $2 \mathrm{~b})$. In the righting reflex test (Fig. $2 \mathrm{c}$ ), the two-way ANOVA showed no main effect of VPA treatment $\left(F_{1,42}=2.471, \quad p=0.123\right)$ and no VPA
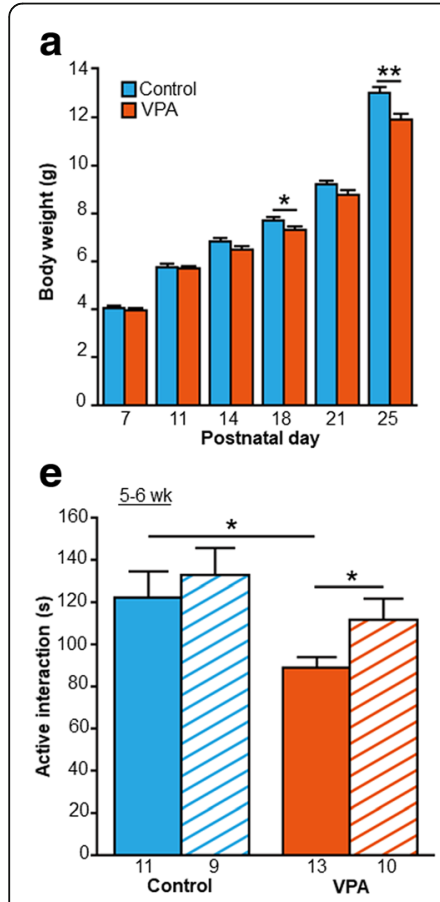

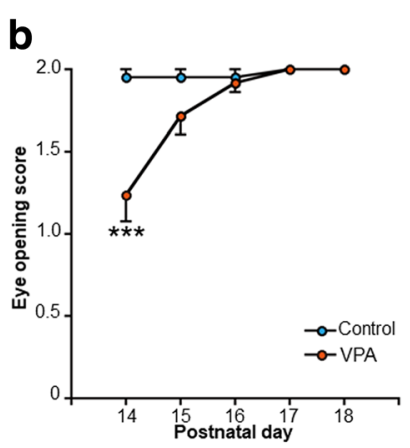

f

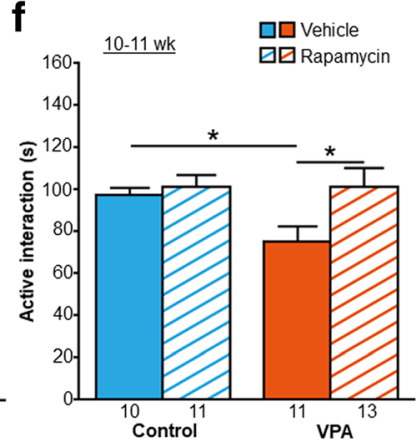

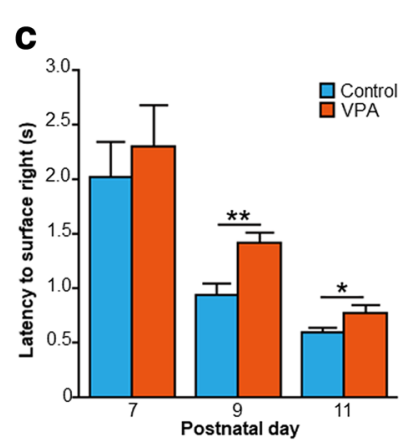

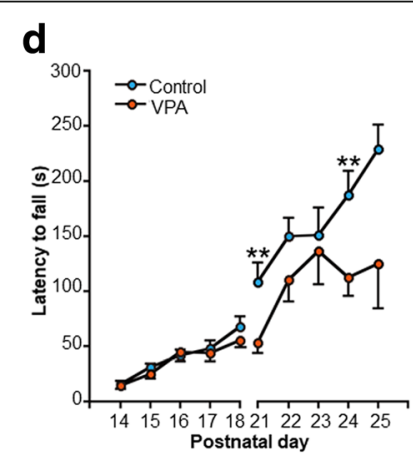

g

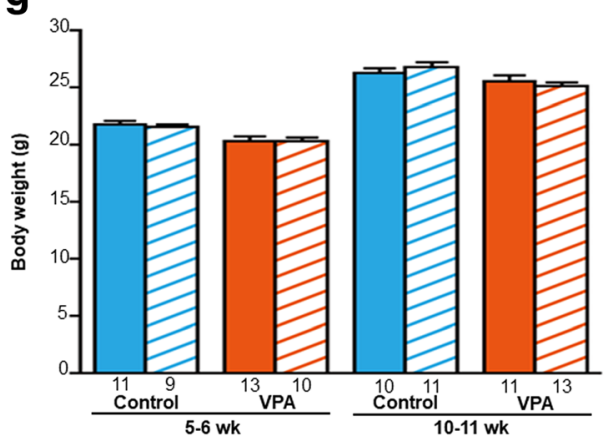

Fig. 2 Body maturation, motor function, and effects of rapamycin treatment on social interaction and body weight. (a) Valproic acid-exposed mice exhibited lower body weight on P18 and P25. (b) Valproic acid-exposed mice had lower eye-opening scores on P14. (c) Valproic acidexposed mice exhibited a longer latency to right on P9 and P11 in righting reflex test. (d) Valproic acid-exposed mice exhibited a shorter latency to fall from P21 to P25 in the hanging wire test. (e) Social interaction test (5-6 weeks of age). Vehicle-treated VPA-exposed mice exhibited a decrease in active social interaction time compared with vehicle-treated control mice. Rapamycin-treated VPA-exposed mice exhibited an increase in active social interaction time compared with vehicle-treated VPA-exposed mice. (f) Social interaction test (10-11 weeks of age). Vehicle-treated VPA-exposed mice exhibited a decrease in active social interaction time compared with vehicle-treated control mice. Rapamycintreated VPA-exposed mice exhibited an increase in active social interaction time compared with vehicle-treated VPA-exposed mice. (g) No significant difference in body weight was found between vehicle treatment and rapamycin treatment. Administration of rapamycin for 2 consecutive days did not affect body weight. Significant differences in body weight were found between control and VPA-exposed mice in both adolescence and adulthood. Error bars indicate SEM. ${ }^{*} p<0.05,{ }^{* *} p<0.01,{ }^{* *} p<0.001$ 
treatment $\times$ postnatal day interaction $\left(F_{2.026,42}=0.294\right.$, $p=0.620 ; n=21$ control mice, $n=24$ VPA-exposed mice). Both groups (i.e., exposed to VPA or saline) exhibited a progressive decline in the latency to right on P7, P9, and P11 $\left(F_{2.026,42}=0.294, p=0.620\right)$. The two-way ANOVA showed no main effect of VPA treatment $\left(F_{1,24}=0.371, p=0.548\right)$ and no VPA treatment $\times$ postnatal day interaction $\left(F_{3.054,24}=0.355, p=0.790\right)$. The Bonferroni post hoc test showed a significantly longer latency in VPA-exposed mice on P9 and P11 (P9: $p=0.001$; P11: $p=0.046$ ). Both groups (i.e., exposed to VPA or saline) exhibited a progressive increase in the latency to fall on P14-18 $\left(F_{3.054,24}=\right.$ 16.621, $p=0.000$; Fig. 2d). The two-way ANOVA revealed a significant main effect of VPA treatment on the latency to fall on P21-25 $\left(F_{1,22}=12.250, p=\right.$ $0.002)$, with no main effect of postnatal day $\left(F_{2.835,22}\right.$ $=2.703, p=0.056)$ and no VPA treatment $\times$ postnatal day interaction $\left(F_{2.835,22}=0.626, p=0.592\right)$. The Bonferroni post hoc test showed a significantly shorter latency to fall in VPA-exposed mice on P21 and P24 (P21: $p=0.001$; P24: $p=0.001$ ).

We assessed the effects of rapamycin treatment on social interaction in control and VPA-exposed mice during both adolescence and adulthood. In adolescence (Fig. 2e), vehicle-treated VPA-exposed mice exhibited a decrease in active social interaction time compared with vehicletreated control mice $\left(t_{22}=2.669, p=0.014 ; n=11\right.$ vehicle-treated control mice, $n=13$ vehicle-treated VPAexposed mice). Active social interaction time in rapamycin-treated VPA-exposed mice significantly increased compared with vehicle-treated VPA-exposed mice $\left(t_{21}=-2.134, \quad p=0.045 ; \quad n=13\right.$ vehicle-treated VPA-exposed mice, $n=10$ rapamycin-treated VPA-exposed mice). No significant difference in active social interaction time was found between vehicle-treated control mice and rapamycin-treated control mice $\left(t_{18}\right.$ $=-0.599, p=0.557 ; n=11$ vehicle-treated control mice, $n=9$ rapamycin-treated control mice). In adulthood (Fig. 2f), vehicle-treated VPA-exposed mice exhibited a decrease in active social interaction time compared with vehicle-treated control mice $\left(t_{19}=2.586, p=0.018 ; n=10\right.$ vehicle-treated control mice, $n=11$ vehicle-treated VPA-exposed mice). Rapamycin-treated VPA-exposed mice exhibited an increase in active social interaction time compared with vehicle-treated VPA-exposed mice $\left(t_{22}=-2.284, p=0.032 ; n=11\right.$ vehicle-treated VPA-exposed mice, $n=13$ rapamycin-treated VPA-exposed mice). No significant difference in active social interaction time was found between vehicle-treated control mice and rapamycin-treated control mice $\left(t_{21}=-0.415, p=0.682 ; n=10\right.$ vehicle-treated control mice, $n=11$ rapamycin-treated control mice). Body weight was recorded immediately before the social interaction test (Fig. 2g). A significant difference in body weight was found between control and VPA-exposed mice in adolescence (5-6 weeks of age; vehicle-treated control mice vs. vehicle-treated VPA-exposed mice, $t_{22}=$ 3.226, $p=0.004$; rapamycin-treated control mice vs. rapamycin-treated VPA-exposed mice, $t_{19}=-3.255, p$ $=0.004$ ), with no significant difference between vehicle-treated control mice vs. rapamycin-treated control mice $\left(t_{19}=0.610, p=0.549\right)$ or between vehicle-treated VPA-exposed mice vs. rapamycin-treated VPA-exposed mice $\left(t_{22}=0.617, p=0.869\right)$. In adulthood (10-11 weeks of age), rapamycin-treated VPA-exposed mice exhibited lower body weight than rapamycin-treated control mice $\left(t_{20.846}=-2.941, p=0.008\right)$. No significant difference in body weight was found between vehicle-treated control mice and vehicle-treated VPA-exposed mice $\left(t_{19}=1.005\right.$, $p=0.327)$. No significant difference in body weight was found between vehicle-treated control mice vs. rapamycin-treated control mice $\left(t_{19}=-0.899, p=0.380\right)$ or between vehicle-treated VPA-exposed mice vs. rapamycintreated VPA-exposed mice $\left(t_{22}=0.753, p=0.459\right)$.

\section{Effects of VPA exposure in utero on gene expression}

Vehicle-treated VPA-exposed mice $(n=5)$ exhibited the differential expression of 5644 genes (2761 upregulated genes, 2883 downregulated genes) compared with vehicle-treated control mice $(n=5$; Table 1 ; for information for each gene, see Additional file 1: Table S1a). We detected associations between the up- and downregulated genes in VPA-exposed mice and curated studies of Diseases, Compounds, and Knockout mice in the BaseSpace database. As shown in Additional file 2: Table S2a, we found that 148 diseases were positively correlated with upregulated genes using the BaseSpace Diseases atlas application. Vitamin D deficiency, which is a Nutritional and Metabolic Disease, had the highest score (96.94107042). Within the top five in the score list, we found Developmental Disorder and Developmental Delay (score $=82.71872854$ ). We found that 136 diseases were positively correlated with downregulated genes using the BaseSpace Diseases atlas application. Injury of the eye region, which is an Eye Disorder, had the highest score (92.03862769).

Table 1 Number of genes with altered expression in each group

\begin{tabular}{llll}
\hline Group & $\begin{array}{l}\text { Total altered } \\
\text { genes }\end{array}$ & $\begin{array}{l}\text { Upregulated } \\
\text { genes }\end{array}$ & $\begin{array}{l}\text { Downregulated } \\
\text { genes }\end{array}$ \\
\hline $\begin{array}{l}\text { VPA + vehicle/ } \\
\text { Control + vehicle }\end{array}$ & 5644 & 2761 & 2883 \\
$\begin{array}{l}\text { VPA + rapamycin/ } \\
\text { VPA + vehicle }\end{array}$ & 23 & 7 & 16 \\
$\begin{array}{l}\text { Control + rapamycin/ } \\
\text { Control + vehicle }\end{array}$ & & - & - \\
\hline
\end{tabular}


The BaseSpace Pharmaco atlas application showed that 387 compounds were positively correlated with upregulated genes (Additional file 2: Table S2b). Glycidol had the highest score (100). The BaseSpace Pharmaco atlas application showed that 446 compounds were positively correlated with downregulated genes. Ozagrel had the highest score (84.66459954). The BaseSpace Knockout atlas application showed that $26 \mathrm{KO}$ mice were positively correlated with upregulated genes (Additional file 2: Table S2c). PRKG1 had the highest score (93.20344653). The BaseSpace Knockout atlas application showed that $25 \mathrm{KO}$ mice were positively correlated with downregulated genes. PRKG1 had the highest score (79.58880595).

\section{Expression of genes associated with mTOR signaling pathway}

We found 5644 significantly altered genes (2761 upregulated genes, 2883 downregulated genes) between vehicle-treated control mice (control + vehicle) and vehicle-treated VPA-exposed mice (VPA + vehicle; Table 1). Twenty-three genes (seven upregulated genes, 16 downregulated genes; for information for each gene, see Additional file 1: Table S1b) were differentially expressed in rapamycin-treated VPA-exposed mice (VPA + rapamycin, $n=5)$ compared with vehicle-treated VPA-exposed mice (VPA + vehicle, $n=5)$. No significantly altered genes were found between rapamycin-treated control mice (control + rapamycin, $n=5$ ) and vehicle-treated control mice (control + vehicle, $n=5$ ). Altered genes that are associated with the mTOR signaling pathway between vehicle-treated control mice and vehicle-treated VPA-exposed mice were extracted from Pathway Enrichment of BaseSpace (Table 2). mTOR, Mapk1, Rps6ka3, Akt2, and Pick3cg had fold changes $>1.2$ or $<-1.2$. These genes in the mTOR pathway (Table 2) were unaltered between vehicle-treated VPA-exposed mice and rapamycin-treated VPA-exposed mice.

\section{Characteristics of gene expression induced by rapamycin treatment}

Figure 3 presents a Venn diagram of significantly altered gene expression in vehicle-treated VPA-exposed mice (VPA + vehicle) vs. vehicle-treated control mice (control + vehicle; 5644 genes) and rapamycin-treated VPA-exposed mice (VPA + rapamycin) vs. vehicletreated VPA-exposed mice (VPA + vehicle; 23 genes). We found 11 common genes (Msl1, Sly, LOC100504642, LOC380994, 4921509O09Rik, Gm14625, A330094K $24 R i k$, Fyb, two genes that have no gene symbols, and Sly that has two probes; Fig. 3). Msl1 expression increased in both vehicle-treated VPA-exposed mice vs. vehicle-treated control mice (VPA + vehicle/control + vehicle) and rapamycin-treated VPA-exposed mice vs. vehicle-treated VPA-exposed mice (VPA + rapamycin/
Table 2 Expression change in mTOR signaling pathwayassociated genes in vehicle-treated VPA-exposed mice and vehicle-treated control mice

\begin{tabular}{|c|c|c|c|}
\hline Gene & EntrezGene ID & Imported ID & Fold change \\
\hline Mtor & 56,717 & A_52_P67643 & -1.5175 \\
\hline Mapk1 & 26,413 & A_55_P1973339 & -1.2254 \\
\hline Rheb & 19,744 & A_55_P2129034 & -1.1928 \\
\hline Rps6kb1 & 72,508 & A_55_P2019083 & -1.173 \\
\hline Cab39 & 12,283 & A_51_P230934 & -1.163 \\
\hline Pld2 & 18,806 & A_55_P2049572 & -1.1607 \\
\hline Eif4al & 13,681 & A_55_P2046398 & -1.158 \\
\hline Yy1 & 22,632 & A_55_P2107745 & -1.1493 \\
\hline Cab39l & 69,008 & A_55_P2001948 & -1.1442 \\
\hline Rheb & 19,744 & A_55_P2170139 & -1.1396 \\
\hline Atg13 & 51,897 & A_55_P2028394 & -1.135 \\
\hline TsCl & 64,930 & A_55_P2157695 & -1.132 \\
\hline Pik3cd & 18,707 & A_52_P99848 & -1.1195 \\
\hline Ppp2ca & 19,052 & A_55_P2288117 & -1.1053 \\
\hline Raf1 & 110,157 & A_55_P1973643 & -1.09 \\
\hline Ulk1 & 22,241 & A_55_P1977314 & -1.084 \\
\hline Pik3r3 & 18,710 & A_55_P2000158 & -1.0813 \\
\hline Rhoa & 11,848 & A_55_P2008081 & -1.0709 \\
\hline Racl & 19,353 & A_55_P2076489 & -1.0697 \\
\hline Ywhaq & 22,630 & A_55_P2142296 & -1.0651 \\
\hline Fbxw11 & 103,583 & A_51_P141860 & -1.0642 \\
\hline Mapkap 1 & 227,743 & A_55_P2046363 & 1.0597 \\
\hline Map2k1 & 26,395 & A_51_P241074 & 1.0611 \\
\hline Eif4g2 & 13,690 & A_51_P306066 & 1.0807 \\
\hline Eif4g3 & 230,861 & A_55_P2034372 & 1.0837 \\
\hline Rps6 & 20,104 & A_55_P1955239 & 1.0851 \\
\hline Racl & 19,353 & A_51_P513254 & 1.0907 \\
\hline Ywhaq & 22,630 & A_65_P16952 & 1.0955 \\
\hline Eif4gl & 208,643 & A_55_P2046378 & 1.1071 \\
\hline Rragc & 54,170 & A_51_P346826 & 1.1071 \\
\hline Stk11 & 20,869 & A_55_P2166399 & 1.1071 \\
\hline Eif $4 b$ & 75,705 & A_51_P151271 & 1.1223 \\
\hline Clip1 & 56,430 & A_55_P2006519 & 1.1358 \\
\hline Vegfa & 22,339 & A_52_P638895 & 1.1535 \\
\hline Vegfb & 22,340 & A_52_P436628 & 1.155 \\
\hline Eif4ebp 1 & 13,685 & A_51_P330428 & 1.1939 \\
\hline Vegfa & 22,339 & A_52_P249424 & 1.1976 \\
\hline Rps6ka3 & 110,651 & A_55_P2404434 & 1.2021 \\
\hline Akt2 & 11,652 & A_55_P2066523 & 1.2491 \\
\hline Pik3cg & 30,955 & A_51_P507832 & 1.3404 \\
\hline
\end{tabular}




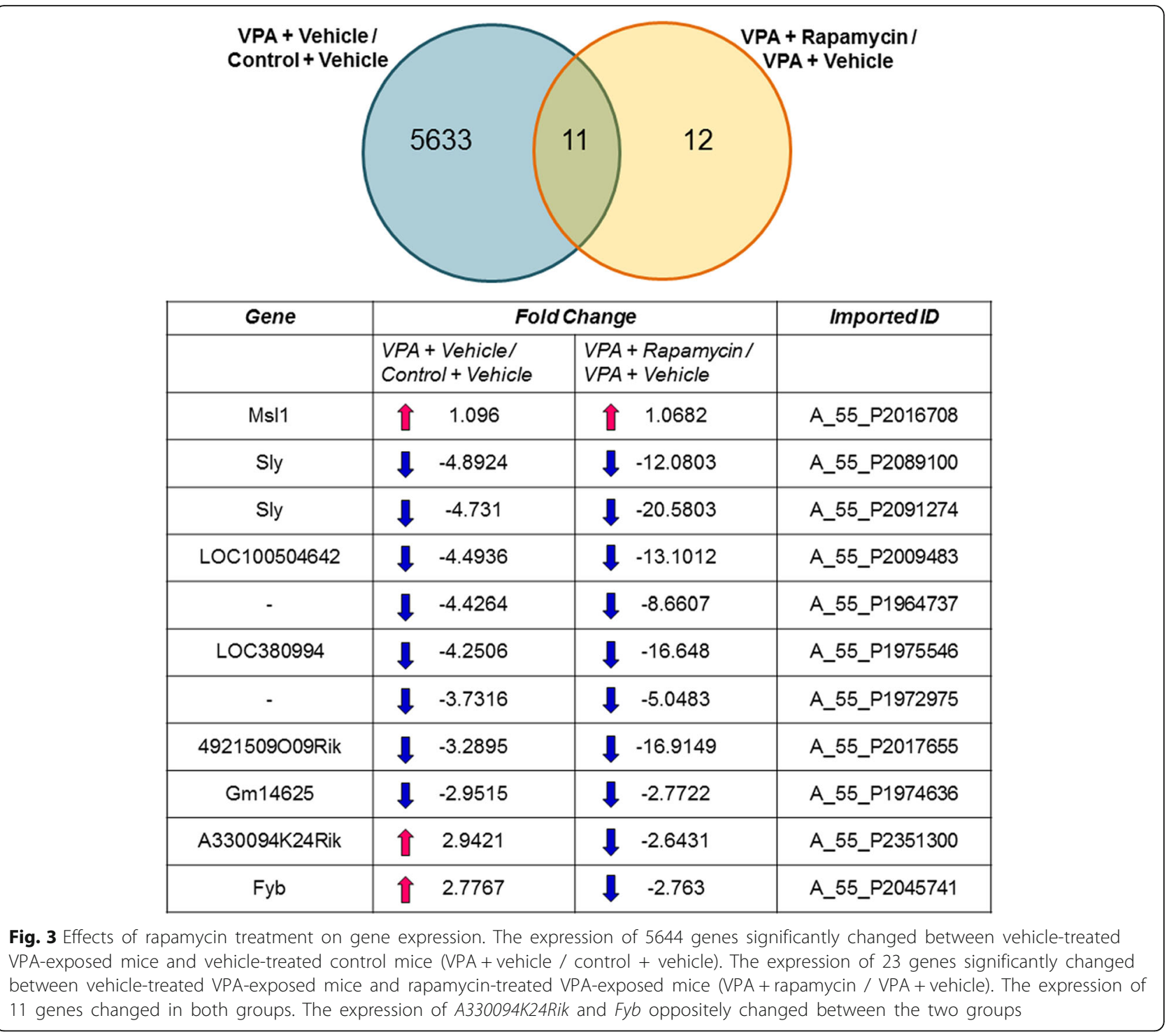

VPA + vehicle). Sly, LOC100504642, LOC380994, 49 21509009Rik, Gm14625, and two genes without gene symbols decreased in both vehicle-treated VPA-exposed mice vs. vehicle-treated control mice (VPA + vehicle / control + vehicle) and rapamycin-treated VPA-exposed mice vs. vehicle-treated VPA-exposed mice (VPA + rapamycin/VPA + vehicle). A330094K24Rik and Fyb increased in vehicle-treated VPA-exposed mice vs. vehicle-treated control mice (VPA + vehicle / control + vehicle) but decreased in rapamycin-treated VPA-exposed mice vs. vehicle-treated VPA-exposed mice (VPA + rapamycin / VPA + vehicle). Furthermore, we investigated networks of A330094K24Rik and Fyb using "build networks" in MetaCore. We were unable to detect networks for A330094K24Rik but found that Fyb was in networks that are associated with $p 70 S 6$, which is downstream of the mTOR signaling pathway (Fig. 4; $F y b$ is also referred to as SLAP-130 or ADAP).

\section{Expression and phosphorylation levels of $\mathrm{S} 6$}

A previous study reported that rapamycin treatment in $\mathrm{TsC1}^{+/-}$and $\mathrm{Tsc}^{2^{+/-}}$mice improved social interaction deficits and decreased the protein level of activated phospho-S6K [21]. The phosphorylation of S6K phosphorylates S6, and this process is associated with protein synthesis [8]. A recent study showed that lymphoblastoid cell lines from patients with idiopathic autism increased S6 phosphorylation compared with controls [36]. Therefore, we analyzed the phosphorylation of S6 protein in whole mouse brains in each group (Fig. 5a). Vehicle-treated VPA-exposed mice exhibited an elevation of phospho-S6 levels compared with vehicle-treated 
control mice $\left(t_{6}=-4.113, p=0.006 ; n=4\right.$ vehicle-treated control mice, $n=4$ vehicle-treated VPA-exposed mice; Fig. 5b). Rapamycin-treated VPA-exposed mice exhibited significant suppression of S6 phosphorylation compared with vehicle-treated VPA-exposed mice $\left(t_{6}=2.910, p=0.027\right.$; $n=4$ vehicle-treated VPA-exposed mice, $n=4$ rapamycintreated VPA-exposed mice). Rapamycin-treated control mice exhibited significant suppression of S6 phosphorylation compared with vehicle-treated control mice $\left(t_{6}=4.331, p=0.005\right.$; $n=4$ vehicle-treated control mice, $n=4$ rapamycin-treated control mice).

\section{Discussion}

In the present study, we found that VPA-exposed mice exhibited a delay in body maturation and poor motor performance compared with control mice. We confirmed that rapamycin treatment improved social interaction deficits in VPA-exposed mice, although these improvements in social interaction deficits may be secondary to improvements in other behaviors. We also found that rapamycin treatment for 2 consecutive days improved social interaction deficits without altering body weight in both adolescence and adulthood. Rapamycin treatment reduced the expression of two genes (Fyb and A330094K24Rik) and S6 protein phosphorylation in vehicle-treated VPA-exposed mice. Furthermore, we found associations between aberrant gene expression in VPA-exposed mice and curated Diseases, Pharmaco, and Knockout mice.

Exposure to VPA in utero in mice and rats has been used to model ASD [37]. Previous studies reported that VPA exposure in utero or in adolescence delayed body maturation and resulted in poor motor performance in both mice and rats [27, 30]. In the present study, we also observed a delay in body maturation and worse motor performance in VPA-exposed mice. These results are consistent with previous studies that reported delays in body maturation and poor motor performance in VPA-exposed mice. An increase or decrease in the expression/phosphorylation of proteins in the mTOR signaling pathway and deficits in social interaction have been reported in VPA-exposed mice and rats. The phosphorylation of Akt, mTOR, 4EBP1, and S6 in the lateral temporal neocortices decreased in VPA-exposed rats [32]. Valproic acid-exposed mice exhibited a decrease in PTEN protein levels and an increase in Akt phosphorylation in the prefrontal cortex and hippocampus on embryonic day 18 and P13 [30]. A recent study reported that VPA-exposed mice exhibited social interaction deficits in the three-chambered social interaction test, a decrease in PTEN protein level, an increase in Akt phosphorylation, and a decrease in the number of Nissl-positive cells in the CA1 area of the hippocampus [38]. These previous results imply that prenatal exposure to VPA causes the aberrant expression/phosphorylation of proteins in the mTOR signaling pathway. In the present study, we also found that vehicle-treated VPA-exposed mice exhibited deficits in social interaction and an increase in S6 protein phosphorylation compared with vehicle-treated control mice. These present results are consistent with previous studies. Rapamycin treatment inhibited apoptosis in the hippocampus in VPA-exposed rats [33]. Qin et al. reported that rapamycin treatment attenuated social interaction deficits and enhanced mTOR and S6 phosphorylation in VPA-exposed rats on P33-35 [34]. These authors also found that treatment with sulindac (an inhibitor of the Wnt signaling pathway) improved social deficits and attenuated the enhancement of mTOR phosphorylation in VPA-exposed rats. Qin et al. suggested that VPA activates both the Wnt and mTOR signaling pathways to induce autism-like behavior. In the present study, the BaseSpace analysis did not reveal an improvement of aberrant Wnt gene expression in the VPA + Vehicle/Control + Vehicle groups vs. VPA + Rapamycin/VPA + Vehicle groups. Further studies are needed to identify the specific pathway that interacts with the mTOR signaling pathway to impair social interaction in VPA-exposed animals. In the present study, we found that rapamycin treatment improved social interactions deficits in VPA-exposed mice in both adolescence and adulthood. Although early treatment is advantageous for improving symptoms of autism in general, our data suggest that rapamycin may be a treatment candidate for ASD patients who are exposed to VPA in utero in both adolescence and adulthood.

Vehicle-treated VPA-exposed mice exhibited the aberrant expression of genes that are associated with the mTOR signaling pathway, and rapamycin treatment did not affect the expression of these genes. Vehicle-treated VPA-exposed mice exhibited an increase in S6 protein phosphorylation compared with vehicle-treated control mice, and rapamycin treatment decreased S6 phosphorylation in VPA-exposed mice. A recent study reported that lymphoblastoid cell lines from patients with idiopathic autism presented an elevation of S6 phosphorylation through an increase in the expression of PI3K catalytic subunit p1108 compared with controls [36]. Rapamycin treatment improved social interaction deficits in $\mathrm{Tsc1}^{+/-}$and $T s 2^{+/-}$mice and attenuated the protein levels of phosphorylated S6K, which phosphorylates S6 protein, in $T s c 2^{+/-}$mice [21]. We speculate that increases in the phosphorylation of S6 are associated with social interaction deficits in animal models of ASD and ASD patients who present an aberrant mTOR signaling pathway.

Meikle et al. (2008) reported that brain levels of rapamycin remained sufficiently high to inhibit mTOR 


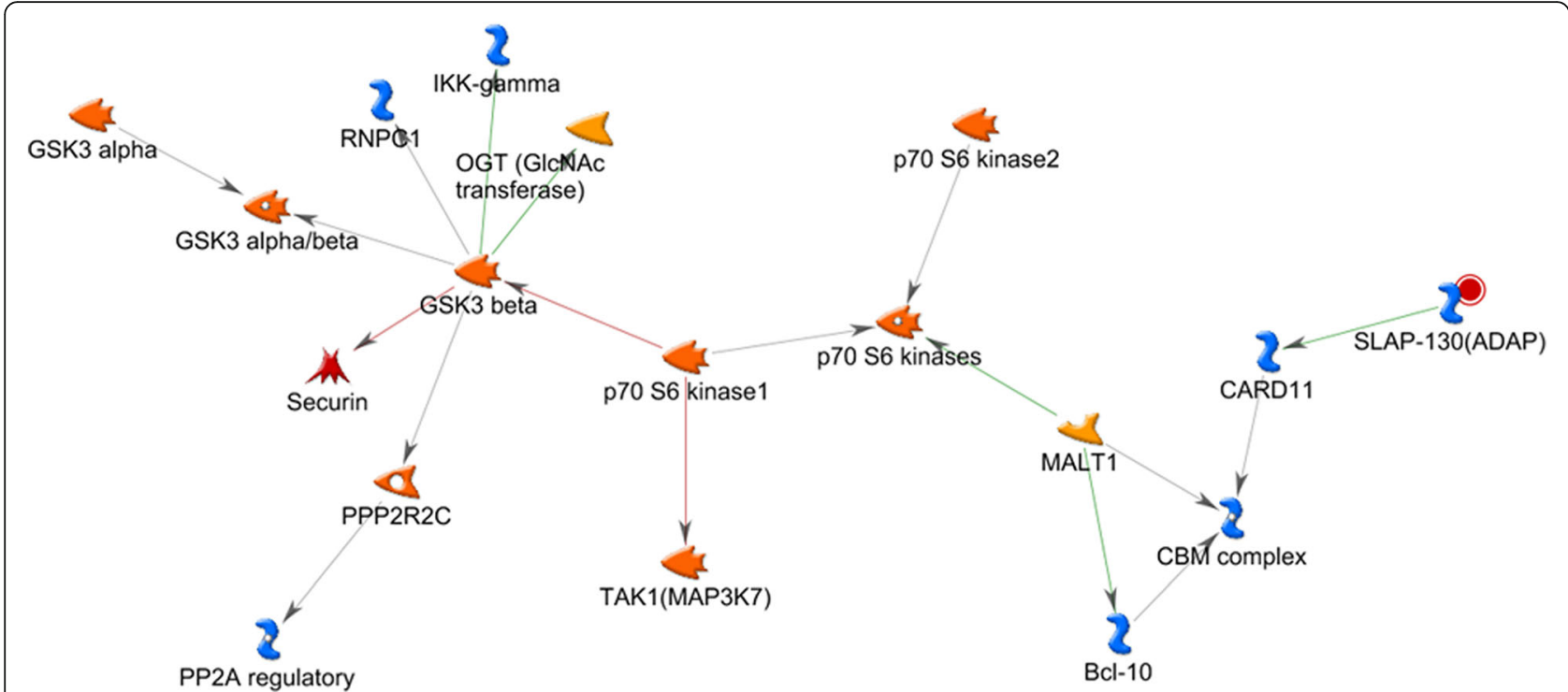

Fig. 4 MetaCore network built from Fyb (SLAP-130 or ADAP). Fyb is also referred to as SLAP-130 or ADAP. The red circle shows Fyb (SLAP-130 or ADAP). The networks that are associated with Fyb were built using "build networks" in MetaCore, and interactions were visualized. In these networks, Fyb is indirectly related to S6K (p70 S6 kinase). BCl-10, B-cell CLL/lymphoma 10; CARD11, caspase recruitment domain family member 11; CBM complex, CARD11-BCl-10-MALT1 signalosome complex; GSK3 alpha, glycogen synthase kinase 3a; GSK3 alpha/beta, glycogen synthase

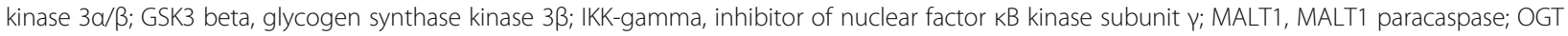
(GlcNAc transferase), O-linked N-acetylglucosamine transferase; p70 S6 kinase, $70 \mathrm{KDa}$ ribosomal protein S6 kinase; p70 S6 kinase 1,70 KDa ribosomal protein $\mathrm{S6}$ kinase 1; p70 S6 kinase 2, $70 \mathrm{KDa}$ ribosomal protein $\mathrm{S6}$ kinase 2; PP2A regulatory, protein phosphatase 2A; PPP2R2C, protein phosphatase 2 regulatory subunit By; RNPC1, RNA binding motif protein 38 (RNPC1 is previous HGNC symbol for RBM38 gene); Securin, Securin is also referred to as pituitary tumor-transforming 1 (PTTG1); TAK1 (MAP3K7), mitogen-activated protein kinase kinase kinase 7 (TAK1 is previous HGNC symbol for MAP3K7)

throughout the $48 \mathrm{~h}$ period after rapamycin administration $(6 \mathrm{mg} / \mathrm{kg}$, i.p. $)$ in mice. Immunoblot analyses of brain lysates that were collected $24 \mathrm{~h}$ after rapamycin administration $(6 \mathrm{mg} / \mathrm{kg}$, i.p.) showed a reduction of $\mathrm{pS} 6$ in $T s c 1{ }^{\text {null-neuron }}$ mice [35]. In the present study, we treated mice with $10 \mathrm{mg} / \mathrm{kg}$ rapamycin. We collected brains on the same day after the end of the social interaction test in adulthood. The brains were immediately frozen in liquid nitrogen after collection and stored at $-80^{\circ} \mathrm{C}$ until Western blot analysis. Thus, we presumed that rapamycin continued to exert its effects in VPA-exposed mice.

The rapamycin-induced improvements in social interaction deficits were transient in VPA-exposed mice, in which we found that the effects of rapamycin treatment disappeared within 5 weeks (see rapamycin-treated VPA-exposed mice in Fig. 2e and vehicle-treated VPA-exposed mice in Fig. 2f). As mentioned above, brain levels of rapamycin remained sufficiently high to inhibit mTOR throughout the $48 \mathrm{~h}$ period after rapamycin administration in mice [35]. This previous study indicates that the effects of rapamycin are still evident 2 days after administration. To our knowledge, no studies have evaluated the effects of rapamycin on improving social interaction deficits longer than 2 days after administration. A rat pharmacokinetic study showed that the $\mathrm{T}_{1 / 2}$ of rapamycin was $14.0 \mathrm{~h}$ for intravenous administration and $33.4 \mathrm{~h}$ for oral administration [39]. In the present study, the effects of rapamycin treatment disappeared within 5 weeks. Further studies are needed to clarify the effects of rapamycin treatment on social interaction deficits by investigating specific treatment periods, doses, timing, combined drugs and therapies, and the duration of the effects.

Valproic acid is a histone deacetylase (HDAC) inhibitor that plays a role in transcriptional regulation [40]. It is used for the treatment of spinal muscular atrophy, in which it increases the survival motor neuron (SMN) protein volume [41]. Valproic acid is associated with the regulation of protein expression. Although VPA does not have $1: 1$ reactivity with $S 6$, the action of the HDAC inhibitor may have influenced the expression of total S6 in the present study.

Overactivation of the mTOR signaling pathway elicits the pathology of ASD. Previous studies and the present data demonstrate overactivation of the mTOR signaling pathway in ASD. To our knowledge, only one other study has reported a decrease in mTOR signaling in VPA-exposed animals [32], but it investigated rats rather than mice, evaluated different brain regions, and assessed the animals at different ages. Future studies should delineate the specific brain regions that are associated with ASD symptoms, and mTOR signaling 


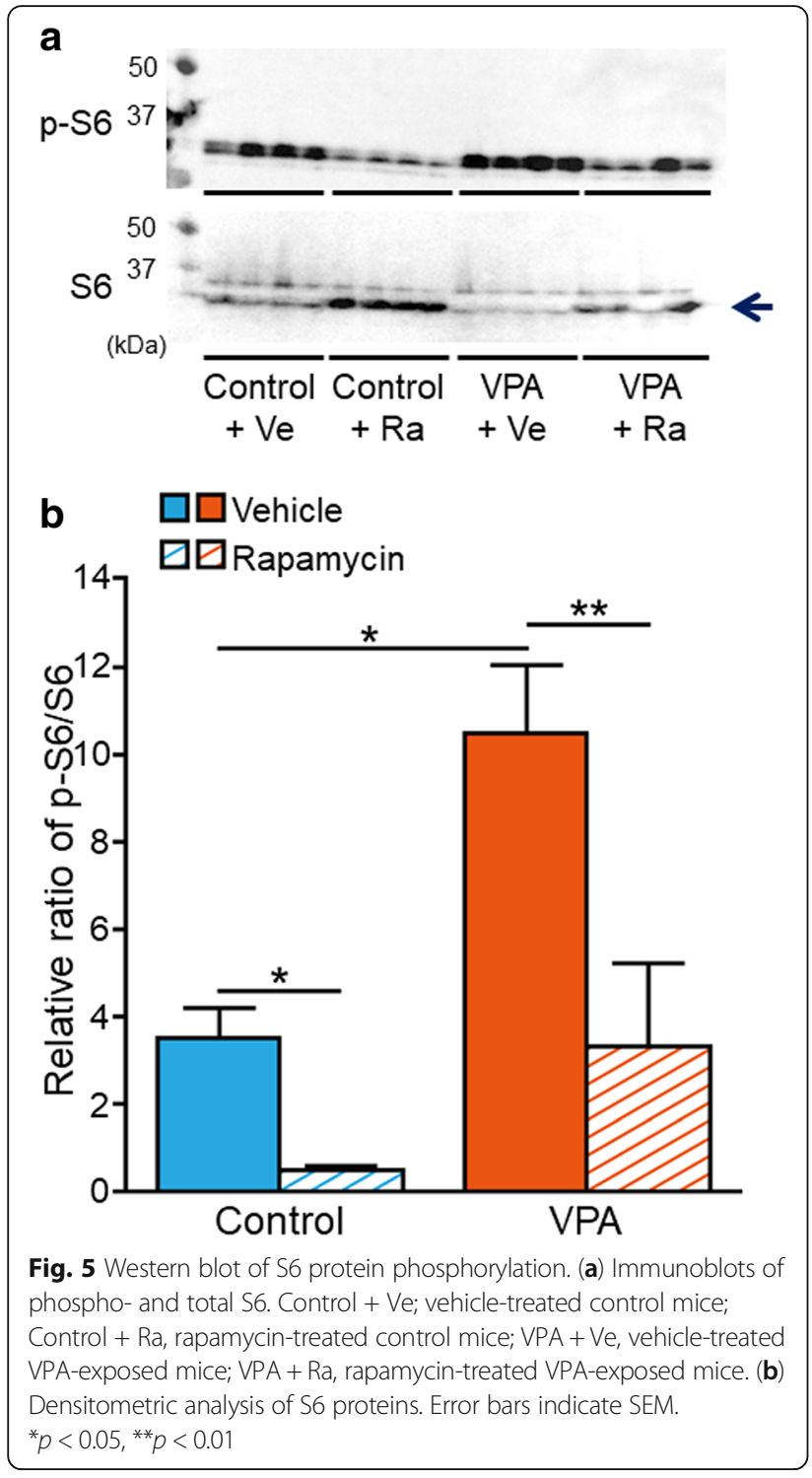

pathways can then be investigated in each of these brain regions.

We found two negatively correlated genes, $F y b$ and A330094K24Rik, between vehicle-treated VPA-exposed mice vs. vehicle-treated control mice and rapamycintreated VPA-exposed mice vs. vehicle-treated VPA-exposed mice. Although A330094K24Rik is registered with Mouse Genome Informatics (http://www.informatics.jax.org/), there is no detected information for A330094K24Rik. Fyb is a FYN binding protein that acts as an adapter protein of FYN [42]. Fyb/SLP-associated protein is a negative regulator of interleukin 2 (IL-2) transcription [43]. IL-2 plays an important role in immunoregulatory functions that are related to the central nervous system and is reportedly associated with ASD [44]. Fyb is a candidate gene in bioinformatic analyses of
ASD [45]. Gera et al. reported that rapamycin treatment decreased the translational ratio of Fyb in LAPC-4 cells in which $\mathrm{AKT}$ is highly phosphorylated by transfection of myristoylated AKT [46]. In the present study, we found that $F y b$ is in the network correlated with S6K, which is downstream of the mTOR signaling pathway (Fig. 4). Fyb in this network is associated with inflammatory cytokine and chemokine production [47]. Cytokines and chemokines play a role in developmental cell death, synapse refinement, and phagocytosis during development [48]. The aberrant expression of cytokines and chemokines is associated with the pathology of ASD [49]. Fyb may be a key molecule in ASD with an aberrant mTOR signaling pathway.

Previous studies analyzed associations between VPA-exposed mice and genes that are associated with ASD [50, 51], but the characteristics of gene expression in whole brains from VPA-exposed mice have not yet been comprehensively investigated. The present study is the first to comprehensively investigate gene expression in VPA-exposed mice. The present study found positive correlations between gene expression in VPA-exposed mouse brains and curated studies of Diseases, Pharmaco, and Knockout mice. Upregulated and downregulated genes have shown positive correlations with 148 and 136 diseases, respectively (Additional file 2: Table S2a). These results indicate that each up- or downregulated gene in VPA-exposed mouse brains showed similarities to Diseases other than ASD. Scores for Vitamin D deficiency and Injury of the eye region were greater than 90. Interestingly, vitamin D deficiency was assessed as a risk factor for ASD [52]. A recent clinical study reported that oral vitamin D supplementation in children for ASD improved Childhood Autism Rating Scale scores compared with the placebo group [53]. Moreover, vitamin $\mathrm{D}$ acts as an inhibitor of the mTOR signaling pathway. Vitamin D activates DNA-damage-inducible transcript 4 (DDIT4), which facilitates activation of the Tsc1/Tsc2 complex; therefore, vitamin $\mathrm{D}$ treatment suppresses downstream mTOR activity [54]. Investigating associations between ASD and the comorbid diseases may be necessary to clarify the pathogenesis of ASD.

Upregulated genes showed a positive correlation with 387 compounds, and downregulated genes showed a positive correlation with 446 compounds. The top compounds with a positive correlation were Glysidol and Ozagrel. Previous studies reported that these compounds were associated with neurogenesis and neurite outgrowth in the developmental mouse brains [55-58]. Although VPA is used to model ASD in animals, unknown is the way in which it causes ASD-like symptoms [59]. Thus, analyzing associations 
between the compounds that are presented in Additional file 2: Table S2b and ASD-like symptoms may contribute to a better understanding of the pathogenesis of ASD that is induced by VPA exposure.

Alterations of the expression of genes (both upregulated genes and downregulated genes) were similar to PRKG1 KO mice (Additional file 2: Table S2c). PRKG1 KO mice are used as a mouse model of sleep disorders [60]. Interestingly, patients with ASD have a high incidence of sleep disturbances [61]. Additionally, a previous study reported that VPA-exposed rats exhibited a disruption of normal sleep architecture and a reduction of the expression levels of GAD65 and GAD67, which are involved in sleep/wakefulness, in cortical tissue [62]. Investigations of ASD-like symptoms in $\mathrm{KO}$ mice and other animal models of ASD will contribute to a better understanding of the pathogenesis of ASD and medication development.

In the present study, we found that rapamycin treatment improved impairments in social interaction in both adolescence and adulthood. The expression of two genes (Fyb and A330094K24Rik) and S6 phosphorylation were reduced by rapamycin treatment. Altogether, these results suggest that an aberrant mTOR signaling pathway is associated with impairments in social interaction in VPA-exposed mice, and rapamycin may be an effective treatment for adolescent and adult patients with not only particular syndromic ASD but also non-syndromic ASD with an aberrant mTOR signaling pathway.

\section{Additional Files}

Additional file 1: Table S1. Gene expression in each group. Gene expression in vehicle-treated VPA-exposed mice / vehicle-treated control mice (a) and rapamycin-treated VPA-exposed mice / vehicle-treated VPA-exposed mice (b). $p$ values were produced by $t$-test comparisons between VPA-treated and control sample (rapamycin-treated and nontreated samples) probeset intensity values. Ranks are based on fold changes. Genes are arranged in descending order of fold change. (XLSX $403 \mathrm{~kb})$

Additional file 2: Table S2. Each atlas application score from BaseSpace. Each individual tab represents Disease, Pharmaco, and Knockout atlas application. (a) Disease atlas application score. (b) Pharmaco atlas application score. (c) Knockout atlas application score. From BaseSpace. (XLSX $59 \mathrm{~kb})$

\section{Abbreviations \\ ASD: autism spectrum disorder; Fyb: FYN binding protein; KO: knockout; MAPK: mitogen-activated protein kinase; mTOR: mammalian/mechanistic target of rapamycin; mTORC1: mTOR complex 1; mTORC2: mTOR complex 2; NF1: neuronal fibromatosis 1; NMDA: N-methyl-D-aspartate; PI3K: phosphatidylinositol-3 kinase; PIKK: phosphatidylinositol-3 kinase (PI3K)- related kinase; PTEN: tensin homolog deleted on chromosome 10; TSC: tuberous sclerosis complex; VPA: valproic acid}

\section{Acknowledgements}

We thank Michael Arends for assistance with editing the manuscript and Etsuko Kamegaya and Yukiko Matsushima for assistance with breeding VPA-exposed mice.

\section{Funding}

This research was supported by Grants-in-Aid for Scientific Research from the Ministry of Education, Culture, Sports, Science and Technology (MEXT) KAKENHI (26860836, 16 K15565, 16H06276, 15H01303) and Japan Agency for Medical Research and Development (AMED; JP16ek0109015).

\section{Availability of data and materials}

Supplemental data are available online. All other data are available from the corresponding author upon request.

\section{Authors' contributions}

$\mathrm{HKM}, \mathrm{KI}, \mathrm{AS}$, and SU designed the experiments. HKM and KI wrote the paper. HKM performed the mouse behavioral testing and analyzed the behavioral data. HKM, HK, and MT analyzed the gene expression data. TK performed the Western blot analysis. YN and YT performed the microarray analysis. HKM and $\mathrm{YH}$ generated a mouse model of ASD by VPA injection and were responsible for breeding management.

\section{Ethics approval and consent to participate}

All of the animal experiments were performed in accordance with the Guidelines for the Care of Laboratory Animals of the Tokyo Metropolitan Institute of Medical Science, and the housing conditions were approved by the Institutional Animal Care and Use Committee.

\section{Consent for publication}

Not applicable.

\section{Competing interests}

The authors declare that they have no competing interests.

\section{Publisher's Note}

Springer Nature remains neutral with regard to jurisdictional claims in published maps and institutional affiliations.

\section{Author details}

'Addictive Substance Project, Tokyo Metropolitan Institute of Medical Science, 2-1-6 Kamikitazawa, Setagaya-ku, Tokyo, Japan. ${ }^{2}$ Department of Biosciences, School of Science and Engineering, Teikyo University, 1-1 Toyosatodai, Utsunomiya-shi, Tochigi, Japan. ${ }^{3}$ Department of Molecular Pathogenesis, Graduate School of Medicine, Juntendo University, 2-1-1 Hongo, Bunkyo-ku, Tokyo, Japan. ${ }^{4}$ Department of Pediatrics, Graduate School of Medicine, The University of Tokyo, 7-3-1 Hongo, Bunkyo-ku, Tokyo, Japan. ${ }^{5}$ Department of Pediatrics, The University of Tokyo Hospital, 7-3-1 Hongo, Bunkyo-ku, Tokyo, Japan. ${ }^{6}$ Department of Developmental Disorders, National Institute of Mental Health, National Center of Neurology and Psychiatry, 4-1-1 Higashimachi, Kodaira-shi, Tokyo, Japan. ${ }^{7}$ Center for Basic Technology Research, Tokyo Metropolitan Institute of Medical Science, 2-1-6 Kamikitazawa, Setagaya-ku, Tokyo, Japan.

Received: 30 September 2018 Accepted: 25 December 2018 Published online: 08 January 2019

\section{References}

1. American Psychiatric Association. Diagnostic and statistical manual of mental disorders. 5th ed. Washington DC: American Psychiatric Publishing; 2013. p. 50-9.

2. Constantino JN. The quantitative nature of autistic social impairment. Pediatr Res. 2011;69:55R-62R

3. Kim YS, Leventhal BL, Koh YJ, Fombonne E, Laska E, Lim EC, et al. Prevalence of autism spectrum disorders in a total population sample. Am J Psychiatry. 2011;168:904-12.

4. Russell G, Rodgers LR, Ukoumunne OC, Ford T. Prevalence of parentreported ASD and ADHD in the UK: findings from the millennium cohort study. J Autism Dev Disord. 2014;44:31-40.

5. Christensen DL, Baio J, Van Naarden Braun K, Bilder D, Charles J, Constantino JN, et al. Prevalence and characteristics of autism spectrum disorder among children aged 8 years: autism and developmental disabilities monitoring network, 11 sites, United States, 2012. MMWR Surveill Summ. 2016;65:1-23.

6. Werling DM, Geschwind DH. Sex differences in autism spectrum disorders. Curr Opin Neurol. 2013;26:146-53. 
7. Varghese M, Keshav N, Jacot-Descombes S, Warda T, Wicinski B, Dickstein $\mathrm{DL}$, et al. Autism spectrum disorder: neuropathology and animal models. Acta Neuropathol. 2017;134:537-66.

8. Xiong $Y$, Sheen J. The role of target of rapamycin signaling networks in plant growth and metabolism. Plant Physiol. 2014;164:499-512.

9. Heitman J, Movva NR, Hall MN. Targets for cell cycle arrest by the immunosuppressant rapamycin in yeast. Science. 1991;253:905-9.

10. Laplante M, Sabatini DM. mTOR signaling in growth control and disease. Cell. 2012;149:274-93.

11. Costa-Mattioli M, Monteggia LM. mTOR complexes in neurodevelopmental and neuropsychiatric disorders. Nat Neurosci. 2013;16:1537-43.

12. de Vries PJ, Hunt A, Bolton PF. The psychopathologies of children and adolescents with tuberous sclerosis complex (TSC): a postal survey of UK families. Eur Child Adolesc Psychiatry. 2007;16:16-24.

13. Silverman $J$, Yang M, Lord C, Crawley JN. Behavioural phenotyping assays for mouse models of autism. Nat Rev Neurosci. 2010;11:490-502.

14. Goorden SM, van Woerden GM, van der Weerd L, Cheadle JP, Elgersma Y. Cognitive deficits in $\mathrm{TSCl}^{+/-}$mice in the absence of cerebral lesions and seizures. Ann Neurol. 2007;62:648-55.

15. Rubenstein JL, Merzenich MM. Model of autism: increased ratio of excitation/ inhibition in key neural systems. Genes Brain Behav. 2003;2:255-67.

16. Bateup HS, Johnson CA, Denefrio CL, Saulnier JL, Kornacker K, Sabatini BL. Excitatory/inhibitory synaptic imbalance leads to hippocampal hyperexcitability in mouse models of tuberous sclerosis. Neuron. 2013;78:510-22.

17. Page DT, Kuti OJ, Prestia C, Sur M. Haploinsufficiency for Pten and serotonin transporter cooperatively influences brain size and social behavior. Proc Natl Acad Sci U S A. 2009;106:1989-94.

18. Kwon CH, Luikart BW, Powell CM, Zhou J, Matheny SA, Zhang W, et al. Pten regulates neuronal arborization and social interaction in mice. Neuron. 2006; 50:377-88.

19. Molosh Al, Johnson PL, Spence JP, Arendt D, Federici LM, Bernabe C, et al. Social learning and amygdala disruptions in $\mathrm{Nf1}$ mice are rescued by blocking p21-activated kinase. Nat Neurosci. 2014;17:1583-90.

20. Ehninger D, Han S, Shilyansky C, Zhou Y, Li W, Kwiatkowski DJ, et al. Reversal of learning deficits in a $\mathrm{TsC}^{+/-}$mouse model of tuberous sclerosis. Nat Med. 2008;14:843-8.

21. Sato A, Kasai S, Kobayashi T, Takamatsu Y, Hino O, Ikeda K, et al. Rapamycin reverses impaired social interaction in mouse models of tuberous sclerosis complex. Nat Commun. 2012;3:1292.

22. Tang G, Gudsnuk K, Kuo SH, Cotrina ML, Rosoklija G, Sosunov A, et al. Loss of mTOR-dependent macroautophagy causes autistic-like synaptic pruning deficits. Neuron. 2014;83:1131-43.

23. Zhou J, Blundell J, Ogawa S, Kwon CH, Zhang W, Sinton C, et al. Pharmacological inhibition of mTORC1 suppresses anatomical, cellular, and behavioral abnormalities in neural-specific Pten knock-out mice. J Neurosci. 2009;29:1773-83

24. Hwang SK, Lee JH, Yang JE, Lim CS, Lee JA, Lee YS, et al. Everolimus improves neuropsychiatric symptoms in a patient with tuberous sclerosis carrying a novel TSC2 mutation. Mol Brain. 2016;9:56.

25. Christensen J, Grønborg TK, Sørensen MJ, Schendel D, Parner ET, Pedersen $\mathrm{LH}$, et al. Prenatal valproate exposure and risk of autism spectrum disorders and childhood autism. JAMA. 2013;309:1696-703.

26. Schneider T, Przewłocki R. Behavioral alterations in rats prenatally exposed to valproic acid: animal model of autism. Neuropsychopharmacology. 2005; 30:80-9.

27. Wagner GC, Reuhl KR, Cheh M, McRae P, Halladay AK. A new neurobehavioral model of autism in mice: pre- and postnatal exposure to sodium valproate. J Autism Dev Disord. 2006;36:779-93.

28. Kataoka S, Takuma K, Hara Y, Maeda Y, Ago Y, Matsuda T. Autism-like behaviours with transient histone hyperacetylation in mice treated prenatally with valproic acid. Int J Neuropsychopharmacol. 2013;16:91-103.

29. Gurpur PB, Liu J, Burkin DJ, Kaufman SJ. Valproic acid activates the PI3K/Akt/ mTOR pathway in muscle and ameliorates pathology in a mouse model of Duchenne muscular dystrophy. Am J Pathol. 2009;174:999-1008.

30. Yang EJ, Ahn S, Lee K, Mahmood U, Kim HS. Early behavioral abnormalities and perinatal alterations of PTEN/AKT pathway in valproic acid autism model mice. PLoS One. 2016;11:e0153298.

31. Kang J, Kim E. Suppression of NMDA receptor function in mice prenatally exposed to valproic acid improves social deficits and repetitive behaviors. Front Mol Neurosci. 2015;8:17.
32. Nicolini C, Ahn Y, Michalski B, Rho JM, Fahnestock M. Decreased mTOR signaling pathway in human idiopathic autism and in rats exposed to valproic acid. Acta Neuropathol Commun. 2015;3:3.

33. Zhang J, Zhang JX, Zhang QL. PI3KNAKT/mTOR-mediated autophagy in the development of autism spectrum disorder. Brain Res Bull. 2016;125:152-8.

34. Qin L, Dai $X$, Yin Y. Valproic acid exposure sequentially activates Wnt and mTOR pathways in rats. Mol Cell Neurosci. 2016;75:27-35.

35. Meikle L, Pollizzi K, Egnor A, Kramvis I, Lane H, Sahin M, et al. Response of a neuronal model of tuberous sclerosis to mammalian target of rapamycin (mTOR) inhibitors: effects on mTORC1 and Akt signaling lead to improved survival and function. J Neurosci. 2008;(21):5422-32.

36. Poopal AC, Schroeder LM, Horn PS, Bassell GJ, Gross C. Increased expression of the PI3K catalytic subunit p110 10 underlies elevated S6 phosphorylation and protein synthesis in an individual with autism from a multiplex family. Mol Autism. 2016;7:3.

37. Mabunga DF, Gonzales EL, Kim JW, Kim KC, Shin CY. Exploring the validity of valproic acid animal model of autism. Exp Neurobiol. 2015;24:285-300.

38. Mahmood U, Ahn S, Yang EJ, Choi M, Kim H, Regan P, et al. Dendritic spine anomalies and PTEN alterations in a mouse model of VPA-induced autism spectrum disorder. Pharmacol Res. 2018;128:110-21.

39. Chen YW, Smith ML, Sheets M, Ballaron S, Trevillyan JM, Burke SE, et al. Zotarolimus, a novel sirolimus analogue with potent anti - proliferative activity on coronary smooth muscle cells and reduced potential for systemic immunosuppression. J Cardiovasc Pharmacol. 2007;49:228-35.

40. Göttlicher M, Minucci S, Zhu P, Krämer OH, Schimpf A, Giavara S, et al. Valproic acid defines a novel class of HDAC inhibitors inducing differentiation of transformed cells. EMBO J. 2001;20:669-78.

41. Seo J, Howell MD, Singh NN, Singh RN. Spinal muscular atrophy: an update on therapeutic progress. Biochim Biophys Acta. 2013;1832:2180-90.

42. Liu J, Kang H, Raab M, da Silva AJ, Kraeft SK, Rudd CE. FYB (FYN binding protein) serves as a binding partner for lymphoid protein and FYN kinase substrate SKAP55 and a SKAP55-related protein in T cells. Proc Natl Acad Sci U S A. 1998;95:8779-84.

43. Musci MA, Hendricks-Taylor LR, Motto DG, Paskind M, Kamens J, Turck CW, et al. Molecular cloning of SLAP-130, an SLP-76-associated substrate of the T cell antigen receptor-stimulated protein tyrosine kinases. J Biol Chem. 1997; 272:11674-7.

44. Xu N, Li X, Zhong Y. Inflammatory cytokines: potential biomarkers of immunologic dysfunction in autism spectrum disorders. Mediat Inflamm. 2015;2015:531518.

45. Yonan AL, Palmer AA, Smith KC, Feldman I, Lee HK, Yonan JM, et al. Bioinformatic analysis of autism positional candidate genes using biological databases and computational gene network prediction. Genes Brain Behav. 2003;2:303-20.

46. Gera JF, Mellinghoff IK, Shi Y, Rettig MB, Tran C, Hsu JH, et al. AKT activity determines sensitivity to mammalian target of rapamycin (mTOR) inhibitors by regulating cyclin D1 and c-myc expression. J Biol Chem. 2004;279:2737-46.

47. Rajasekaran K, Kumar P, Schuldt KM, Peterson EJ, Vanhaesebroeck B, Dixit V, et al. Signaling by Fyn-ADAP via the Carma1-Bcl-10-MAP3K7 signalosome exclusively regulates inflammatory cytokine production in NK cells. Nat Immunol. 2013;14:1127-36.

48. Deverman BE, Patterson PH. Cytokines and CNS development. Neuron. 2009:64:61-78.

49. Young AM, Chakrabarti B, Roberts D, Lai MC, Suckling J, Baron-Cohen S. From molecules to neural morphology: understanding neuroinflammation in autism spectrum condition. Mol Autism. 2016;7:9.

50. Kolozsi E, Mackenzie RN, Roullet Fl, deCatanzaro D, Foster JA. Prenatal exposure to valproic acid leads to reduced expression of synaptic adhesion molecule neuroligin 3 in mice. Neuroscience. 2009;163:1201-10.

51. Kawanai T, Ago Y, Watanabe R, Inoue A, Taruta A, Onaka Y, et al. Prenatal exposure to histone deacetylase inhibitors affects gene expression of autism-related molecules and delays neuronal maturation. Neurochem Res. 2016;41:2574-84.

52. Máčová L, Bičíková M, Ostatníková D, Hill M, Stárka L, Vitamin D. neurosteroids and autism. Physiol Res. 2017;66(Suppl 3):S333-40.

53. Saad K, Abdel-Rahman AA, Elserogy YM, Al-Atram AA, El-Houfey AA Othman HA, et al. Randomized controlled trial of vitamin D supplementation in children with autism spectrum disorder. J Child Psychol Psychiatry. 2018;59:20-9.

54. Lisse TS, Liu T, Irmler M, Beckers J, Chen H, Adams JS, et al. Gene targeting by the vitamin $\mathrm{D}$ response element binding protein 
reveals a role for vitamin $D$ in osteoblast mTOR signaling. FASEB J. 2011;25:937-47.

55. Akane H, Shiraki A, Imatanaka N, Akahori Y, Itahashi M, Ohishi T, et al. Glycidol induces axonopathy by adult-stage exposure and aberration of hippocampal neurogenesis affecting late-stage differentiation by developmental exposure in rats. Toxicol Sci. 2013;134:140-54.

56. Kawashima M, Watanabe Y, Nakajima K, Murayama H, Nagahara R, Jin M, et al. Late effect of developmental exposure to glycidol on hippocampal neurogenesis in mice: loss of parvalbumin-expressing interneurons. Exp Toxicol Pathol. 2017;69:517-26.

57. Aritake S, Oguro H, Iwasa K, Mitaki S, Takayoshi H, Abe S, Onoda K, Yamaguchi S. Clinical efficacy of ozagrel with or without edaravone in 156 acute stroke patients. J Neurol Neuromed. 2017;2:16-9.

58. Sumimoto S, Muramatsu R, Yamashita T. Thromboxane A2 stimulates neurite outgrowth in cerebral cortical neurons via mitogen activated protein kinase signaling. Brain Res. 2015;1594:46-51.

59. Mabunga DF, Gonzales EL, Kim JW, Kim KC, Shin CY. Exploring the validity of Valproic acid animal model of autism. Exp Neurobiol. 2015;24:285-300.

60. Feil R, Hölter SM, Weindl K, Wurst W, Langmesser S, Gerling A, et al. CGMPdependent protein kinase I, the circadian clock, sleep and learning. Commun Integr Biol. 2009;2:298-301.

61. Moore M, Evans V, Hanvey G, Johnson C. Assessment of sleep in children with autism spectrum disorder. Child Aust. 2017;4:72.

62. Cusmano DM, Mong JA. In utero exposure to valproic acid changes sleep in juvenile rats: a model for sleep disturbances in autism. Sleep. 2014;37:1489-99.

Ready to submit your research? Choose BMC and benefit from:

- fast, convenient online submission

- thorough peer review by experienced researchers in your field

- rapid publication on acceptance

- support for research data, including large and complex data types

- gold Open Access which fosters wider collaboration and increased citations

- maximum visibility for your research: over $100 \mathrm{M}$ website views per year

At $\mathrm{BMC}$, research is always in progress.

Learn more biomedcentral.com/submissions 